\title{
The Relationship between Health-related Fitness and Web-based Physical Activity Records in College Students 健康體適能與網路版身體活動量紀錄之關聯
}

\author{
Kuei-Yu CHIEN ${ }^{1}$ Shu-Chen CHEN $^{2}$ Wen-Jong LIN $^{2}$ \\ Hui-Tan $\mathrm{LO}^{3}$ Hung-Jen $\mathrm{CHEN}^{3}$ Mei-Chich $\mathrm{HSU}^{4}$ \\ ${ }^{I}$ Department of Geriatric Health Promotion, \\ Kainan University, TAIWAN \\ ${ }^{2}$ Department of Recreation Sport Management, \\ Yu-Da College of Business, TAIWAN \\ ${ }^{3}$ The Center of General Education, \\ Yu-Da College of Business, TAIWAN \\ ${ }^{4}$ Graduate Institute of Sports Science, \\ National Taiwan Sport University, TAIWAN

\begin{tabular}{|c|c|}
\hline 錢桂玉 & 陳淑貞 ${ }^{2}$ \\
\hline 羅惠丹 3 & 陳鴻仁 ${ }^{3}$ \\
\hline
\end{tabular} \\ ${ }^{1}$ 台灣開南大學銀髮健康促進學系 \\ 2台灣育達商業技術學院休閒運動管理系 \\ ${ }^{3}$ 台灣育達商業技術學院通識教育委員會 \\ ${ }^{4}$ 台灣國立臺灣體育大學(桃園)運動科學研究所
}

\begin{abstract}
The purpose of this study was to investigate the correlation between health-related fitness (HRF) and the physical activity (PA) level from web-based records in college students. The college students $(\mathrm{N}=221,18.8 \pm 0.6 \mathrm{yr})$ were recruited. Sedentary time, exercise mode, duration and rating of perceived exertion scale for 7 days were recorded. The body mass index, sit-ups completed in $30 \mathrm{~s}$ and $60 \mathrm{~s}$, standing long jump, sit and reach, and 800- or 1600-m run/walk were measured. Spearman correlation and independent $t$-test were used for statistics. A level of $\alpha=0.05$ was set for significant on all tests. The results showed that both PA and moderate intensity physical activity were significantly related to HRF, where as cardiovascular endurance was not related. We suggested PA probably affect life movement but not cardiovascular endurance. This study also indicated the correlation patterns were different in gender. The best strategies to promote HRF in college students are to reduce the sedentary time for male and to increase PA intensity for female.
\end{abstract}

Keywords: website, exercise and active life. 


\section{摘 要}

本研究主要探討網路版之身體活動量與大學生健康體適能關聯, 本研究招募221位 (18.8 \pm 0.6 歲) 大學生記錄 7 天靜態生活與 運動種類、時間以及運動時自覺努力的程度，此外進行健康體適能之身體質量指數、一分鐘仰卧起坐、立定跳遠、坐姿體前彎 以及男生 1600 公尺或是女生之 800 公尺跑走測驗。以Spearman 積差相關進行各變數之關聯度檢定, 並以獨立樣本檢定考驗男 生與女生間各變數之差異性, 顯著水準定在 0.05 。結果顯示無論每週平均身體活動時間或是中等強度身體活動時間與非心肺適能 之健康適能具㙷著的關聯, 此結果暗示了身體活動量與日常生活之活動力有關, 與心肺適能無關, 本研究亦發現身體活動量與健 康適能關聯型態因性別不同而有所不同, 本校最佳之男性體適能增進策略為減少坐式時間, 最佳之女性體適能增進策略為增強運 動強度。

\section{關鍵詞：網路，運動，活躍生活}

\section{Introduction}

It is well established leisure-time physical activity benefits health status. Regular physical activity decreases the risk of developing cardiovascular disease, diabetes, some cancers, obesity, osteoporosis, and other chronic conditions (Vandelanotte, Spathonis, Eakin, \& Owen, 2007). To increase physical activity is a key element of healthpromotion strategies in many countries (Haase, Steptoe, Sallis, \& Wardle, 2004). Physical activity decrease is a trend in all over the world. The reasons of physical inactivity were different in various country or culture. There was $19.7 \%$ population of $13-17 \mathrm{yr}$ to do moderate intensity life style physical activity in Taiwan. Moreover, regular physical activity further decreased after school life (Liou, et al., 2005). Physical activity patterns during the young adult years are likely to be the important influences on habitual physical activity and, consequently, have significant implications for long-term health outcomes (Malina, 2001; Sparling, 2003). Late adolescence and early adult life are critical periods of transition (Haase, Steptoe, Sallis, \& Wardle, 2004). Therefore, it is important to monitor physical activity in young adults.

In the past, due to feasibility and cost constraints, most epidemiologists have chosen to use questionnaires for this purpose, and many such questionnaires are available (Hallal, Victora, Wells, \& Lima, 2003). However, there has been an increase in the use of the internet to gather, transform, and disseminate information in recent years. Web-based can provide more advantages in health promotion. And there is substantial evidence that use of web-based interventions do improve behavioral change outcomes. These outcomes included increasing exercise time, increasing knowledge of nutritional status and participation in healthcare, improving body shape perception, and 18-month weight loss maintenance (Wantland, Portillo, Holzemer, Slaughter, \& McGhee, 2004). The purpose of this study was to investigate the relationship between health-related fitness and the physical activity (PA) level from web-based records in college students. This study would be referred for the e-health promotion intervention in college environment.

\section{Methods and Materials}

\section{Subjects and Study Design}

The healthy-college students $(\mathrm{N}=221,18.8 \pm 0.6 \mathrm{yr})$ were recruited from general physical education course. The characteristics of subjects were shown in Table1. Sedentary time, exercise mode, duration and rating of perceived exertion scale (RPE) for 7 days were recorded on the website. After one week later, the body mass index (BMI), timed sit-ups (number completed in $30 \mathrm{~s}$ and $60 \mathrm{~s}$ ), standing long jump, sit and reach and 800and 1600-m run/walk were performed. Timed sit-ups (number completed in $30 \mathrm{~s}$ and $60 \mathrm{~s}$ ) measured abdominal muscular strength and endurance. Standing long jump measured explosive power of the legs. Sit and reach measured lower-back/upper-thigh flexibility. The 800 and 1600-m run/walk measured cardiovascular endurance. Physical education teachers conducted the measurements and testing. The protocols were described in detail in a technical manual from the department of physical education. 


\section{Measurement}

\section{Physical activity record}

Subjects used the ID number and password get into the sedentary and physical activity system on the website of Yu-Da College of Business. They record the sedentary and physical activity for 7 days. The sleeping, eating, reading, watching $\mathrm{TV}$, and computer using time were classified to sedentary time. The mode of physical activity, duration and RPE were included in physical activity record. The RPE score above 12 was defined moderate intensity physical activity (MIPA). Mean of physical activity or sedentary time per day were calculated in hours and minutes.

\section{Health-related physical fitness testing}

We followed the health-related physical fitness testing manual guideline of Ministry of Education. The protocols are as described in Huang \& Malina (2007).

\section{Body mass index (BMI)}

Weight and height were obtained using a stadiometer and digital. All instruments had been verified and approved by the Taiwan Bureau of Standards, Metrology and Inspection. Participants wore light clothes without shoes. Height and weight were measured, and BMI was calculated from the formula: weight $(\mathrm{kg}) /$ height $^{2}\left(\mathrm{~m}^{2}\right)$.

Timed bent-leg sit-ups: abdominal muscular strength and endurance

Each subject lay supine on the mat with knees bent and hands crossed on the chest. The technician held the subject's ankles firmly for support and maintained the count. The subject's elbows had to touch the knee with the same side. After each upward movement, the two sides of scapular returned to touch the mat, but the head did not to touch it. The test was accounted the number of sit-ups performed in $30 \mathrm{sec}$ for abdominal muscular strength and $1 \mathrm{~min}$ for abdominal muscular endurance. In order to minimize error, more than two measurements were taken in the standing long jump, bent-leg curl-ups and sit-and-reach tests.

\section{Standing long jump: leg's muscle strength}

Subjects stood at the starting line and were instructed to jump horizontally forward as far as possible. The width of two legs were small than that of two shoulders. A preparatory crouch before take-off was asked. The distance from the starting line to the heel of the closest foot was recorded. Two trials were recorded, and the better of the two was retained for analysis.

\section{Modified sit and reach: flexibility}

The test was scored as the most distant point (nearest centimeter) reached with the fingertips on the ruler. The device had a measuring scale, with $25 \mathrm{~cm}$ at the level of the feet. Before the test, shoes were removed and subjects were instructed to slowly reach forward with their knees fully extended, as far as possible on the scale. Two trials were recorded, and the better of the two was retained for analysis.

Cardiovascular endurance: 800/1600-m run/ walks

The test was measured in minutes and seconds. Adequate warm-up exercise was advised before the test. When the investigator said, "go," the subjects began the 800/ 1600-m run/walk. The subjects were instructed to try to keep a steady speed and to finish the run as fast as they could. Walking was permitted if a subject could not keep running.

\section{Statistical Analysis}

All analyses were performed using SPSS version 10.0.7 (Chicago, IL). Data were expressed as mean \pm standard deviation (SD). Spearman rank-order correlations were used to examine the associations between different activity levels reported from the website and health-related fitness measured. Independent $t$-test was used to test the results between male and female. A level of $\alpha=0.05$ was set for significance on all tests.

\section{Results}

Body mass index was significantly positive associated with the time of $800 / 1600 \mathrm{~m}$ run/walk (Table 2). Physical activity time was significantly positive associated with time sit-ups and sit and reach performance. In addition, we observed the MIPA time was also significantly positive associated with standing long jump performance. For male subjects, sedentary time was significantly negative associated with standing long jump, timed sit-ups performance. For female subjects, we observed BMI also significantly negative associated with standing long jump. The time of physical activity was positive associated with time sit-ups. The MIPA time were positive timed sit-ups, sit and reach but negative associated with $800 / 1600 \mathrm{~m}$ run/walk time. 
Health related fitness in male was better than in female, except for sit and reach performance (Table 3). There were no difference between male and female students in sedentary and PA time (Table 4). And, MIPA was significantly higher in male than in female students.

\section{Discussion}

Health-related physical fitness include cardiovascular endurance, abdominal muscular strength and endurance, lower back flexibility, and body composition (American Alliance for Health, Physical Education, Recreation and Dance, 1980). The first major finding of this study was that PA level was related to health-related fitness, except for the cardiovascular endurance. It is commonly assumed that a high level of habitual physical activity is associated with higher levels of physical fitness in children, adolescents and adults (Ekelund et al., 2001; U.S. Department of Health and Human Service, 1996). The study showed that the over 72 minutes a week of moderate activity benefit the health (Church, Earnest, Skinner, \& Blair, 2007). It does provide important information on the dose of physical activity in order to improve physical fitness. Our study showed that body mass index was significantly positive associated with the time of $800 / 1600 \mathrm{~m}$ run/walk. It indicated the higher BMI with lower cardiovascular endurance. BMI is a factor that significantly affects the physical fitness of children, adolescents, and adults (Huang \& Malina, 2007). The overweight/obese youngsters tend to have poorer cardiovascular endurance than the normal weight group. Furthermore, the overweight/obese and unfit group had a greater risk of hypertension than other groups (Chen, Fox, Haase, \& Wang, 2006).

We observed that the MIPA time was significantly positive associated with muscle strength in leg. The people selected intensities during the year which regressed toward a common intensity level accompanied by a mean daily exercise RPE of 11.7 to 13.1 (somewhat hard) either in home based program or structure program. The RPE at moderate intensities typically approximates 12-14 (ACSM, 1998; Howley, 2001). Therefore, the RPE scale above 12 was defined as moderate exercise intensity in this study. Jump tests, either a vertical jump test or a standing broad jump test have been widely used in young people for assessing explosive strength. Study had shown an increased level of muscular fitness was associated with a lower CVD risk score (Ortega, Ruiz, Castillo, \& Sjostrom, 2007).
However, we didn't observe the correlation between PA and cardiovascular endurance in all subjects. Previous studies showed that the relationship between activity and fitness is better in adults than in children and adolescents (Malina, 2001). The related habitual physical activity to aerobic fitness in adolescents, conflicting results have been reported (Armstrong, Williams, Balding, Gentle, \& Kirby, 1991; Boreham, Twisk, Savage, Cran, \& Strain, 1997; Katzmarzyk, Malina, Song, \& Bouchard, 1998).

The study showed the correlations between indicators of physical activity and measures of fitness are low to moderate in adolescents or in child (Aaron et al., 1993; Katzmarzyk, Malina, Song, \& Bouchard, 1998). For most individuals, increase in physical activity would increase in physical fitness, although the amount of adaptation in fitness to a standard exercise dose varies widely and is under genetic control (Blair, Cheng, \& Holder, 2001). There is strong evidence for considerable heterogeneity in the responsiveness to regular physical activity. Familial factors also contribute significantly to variability in training response (Bouchard \& Rankinen, 2001). We suggested PA probably affect life movement but not in cardiovascular capacity. Beside, it was to note that there was significantly negative correlation between MIPA and cardiovascular endurance in female students. Activity energy expenditure was significantly and positively related to VO2 peak in female students (Ekelund et al., 2001). The relationship between MIPA and cardiovascular was probably caused to female students have the lower MIPA level (Table 4). When people increase the MIPA, it is effective to enhance the cardiovascular endurance.

The second major finding was the different correlation patterns in gender. For male students, the sedentary time was significantly related with muscle strength and endurance in leg and abdominal (Table 3). Physical activity time and intensity were significantly related with all of health related fitness items in female students. Moreover, health related fitness in male was better than in female, except for sit and reach performance. The study indicated that men presented higher activity levels than women in terms of moderateintensity, vigorous-intensity and total leisure-time physical activity practice (Azevedo, et al., 2007). Our results agree with previous study. This study indicated male did MIPA significantly higher than in female, although there were no differences between male and female in sedentary and physical activity time (Table 4). Therefore, 
we suggested the mode of activity and intensity would be important factors to affect the correlation patterns. It was necessary to supply different strategies for different gender.

Promoting physical activity may be a successful intervention against the epidemic of adult inactivity in school (Azevedo, Araújo, Cozzensa, Silva, \& Hallal,
2007). Earlier and continued intervention will be necessary to offset these declines in physical activity throughout adolescence and adulthood (Caspersen, Pereira, \& Curran, 2000). Our results can be used as makers in order to plan intervention to increase the student level of physical activity. Furthermore, intervention might focus on different aspects, depending on the gender.

Table 1. Subjects Characteristics.

\begin{tabular}{lll}
\hline Parameter & Male $(\mathrm{n}=116)$ & Female $(\mathrm{n}=105)$ \\
\hline Age (years) & $18.8 \pm 0.7$ & $18.8 \pm 0.6$ \\
Height $(\mathrm{cm})$ & $172.3 \pm 4.8$ & $159.3 \pm 5.5$ \\
Weight $(\mathrm{kg})$ & $68.4 \pm 13.0$ & $55.5 \pm 11.1$ \\
Body Mass Index & $22.7 \pm 4.8$ & $21.8 \pm 3.9$ \\
\hline
\end{tabular}

Data are mean $\pm \mathrm{SD}$

Table 2. Correlation between Health-related Fitness and Physical Activity Level.

\begin{tabular}{|c|c|c|c|c|}
\hline Variable & BMI & $\begin{array}{l}\text { Sedentary } \\
\text { (hr/day) }\end{array}$ & $\begin{array}{l}\mathrm{PA} \\
(\mathrm{min} / \mathrm{wk})\end{array}$ & $\begin{array}{l}\text { MIPA } \\
\text { (min/wk) }\end{array}$ \\
\hline \multicolumn{5}{|c|}{$800 / 1600 \mathrm{~m}$ run/walk (min, sec) } \\
\hline All subjects & $0.22^{* *}$ & 0.04 & 0.09 & 0.03 \\
\hline Male & $0.29 *$ & 0.13 & -0.02 & -0.22 \\
\hline Female & $0.33^{* *}$ & -0.20 & -0.11 & $-0.34 * *$ \\
\hline \multicolumn{5}{|c|}{ Standing long jump (m) } \\
\hline All subjects & -0.08 & 0.16 & 0.13 & $0.26^{* *}$ \\
\hline Male & -0.21 & $-0.27 *$ & -0.03 & 0.04 \\
\hline Female & $-0.21^{*}$ & 0.18 & 0.03 & 0.18 \\
\hline \multicolumn{5}{|c|}{ Timed sit-ups (times/30 sec) } \\
\hline All subjects & -0.01 & -0.17 & $0.32^{* *}$ & $0.27^{* *}$ \\
\hline Male & 0.04 & $-0.39 *$ & 0.14 & -0.04 \\
\hline Female & -0.10 & -0.14 & $0.30 * *$ & $0.31 * *$ \\
\hline \multicolumn{5}{|c|}{ Timed sit-ups (times/60 sec) } \\
\hline All subjects & -0.07 & 0.02 & $0.26^{* *}$ & $0.28^{* *}$ \\
\hline Male & -0.12 & $-0.28^{*}$ & 0.17 & 0.02 \\
\hline Female & -0.11 & 0.05 & $0.22 *$ & $0.29 * *$ \\
\hline \multicolumn{5}{|c|}{ Sit and reach $(\mathrm{cm})$} \\
\hline All subjects & 0.05 & 0.12 & $0.19^{*}$ & $0.29^{* *}$ \\
\hline Male & 0.10 & 0.00 & $0.38 * *$ & $0.33^{*}$ \\
\hline Female & 0.03 & $0.23 *$ & 0.13 & $0.34 * *$ \\
\hline
\end{tabular}

Significant correlation was reached between paired variables $(* \mathrm{p}<0.05, * * \mathrm{p}<0.01)$.

BMI, Body mass index; PA, physical activity; MIPA, moderate intensity physical activity (above RPE 12). 
Table 3. Comparison of Health-related Fitness between Male and Female.

\begin{tabular}{lllllc}
\hline & BMI & Standing long jump $(\mathrm{m})$ & $\begin{array}{l}\text { Timed sit-ups } \\
(\text { times/30 sec) }\end{array}$ & $\begin{array}{l}\text { Timed sit-ups } \\
(\text { times/60 } / 5 e c)\end{array}$ & Sit and reach (cm) \\
\hline Male & $22.7 \pm 4.8$ & $2.4 \pm 1.9^{*}$ & $23.3 \pm 4.7^{*}$ & $40.8 \pm 8.9^{*}$ & $25.6 \pm 11.2^{*}$ \\
Female & $21.8 \pm 3.0$ & $1.5 \pm 0.2$ & $16.8 \pm 4.4^{*}$ & $29.7 \pm 8.7$ & $29.1 \pm 9.9$ \\
\hline
\end{tabular}

Data are means $\pm \mathrm{SD}$. * Significantly different from the female group $(\mathrm{p}<0.05)$

Table 4. Comparison of Physical Activity between Male and Female.

\begin{tabular}{llll}
\hline & $\begin{array}{l}\text { Sedentary } \\
(\text { hr/day })\end{array}$ & $\begin{array}{l}\text { PA } \\
(\mathrm{min} / \mathrm{wk})\end{array}$ & $\begin{array}{l}\text { MIPA } \\
(\mathrm{min} / \mathrm{wk})\end{array}$ \\
\hline Male & $18.8 \pm 4.3$ & $126.8 \pm 192.6$ & $125.6 \pm 187.7^{*}$ \\
Female & $17.7 \pm 3.4$ & $87.9 \pm 148.9$ & $58.6 \pm 92.1$ \\
\hline
\end{tabular}

PA, physical activity; MIPA, moderate intensity physical activity (above RPE 12). Data are means \pm SD.

* Significantly different from the female group $(\mathrm{p}<0.05)$.

\section{Reference}

Aaron, D.J., Kriska, A.M., Dearwater, S.R., Anderson, R.L., Olsen, T.L., Cauley, J.A., \& Laporte, R.E. (1993). The epidemiology of leisure physical activity in an adolescent population. Medicine and Science in Sports and Exercise, 25, 847-853.

American alliance for health, physical education, recreation and dance (AAHPERD). (1984). Technical Manual: Health Related Physical Fitness Reston, VA: AAHPERD, 1-47.

American college of sports medicine position stand. (1998). The recommended quantity and quality of exercise for developing and maintaining cardiorespiratory and muscular fitness, and flexibility in healthy adults. Medicine and Science in Sports and Exercise, 30(6), 975-991.

Armstrong, N., Williams, J., Balding, J., Gentle, P., \& Kirby, B. (1991). The peak oxygen uptake of British children with reference to age, sex and sexual maturity. European Journal of Applied Physiology and Occupational Physiology, 62(5), 369-375.

Azevedo, M., Araújo, C., Reichert, F., Siqueira, F., da Silva, M., \& Hallal, P. (2007). Gender differences in leisure-time physical activity. International Journal of
Azevedo, M. R., Araújo, C. L., Cozzensa, d., Silva, M., \& Hallal, P. C. (2007). Tracking of physical activity from adolescence to adulthood: a population- based study. Revista de Saúde Pública, 41, 69-75.

Blair, S. N., Cheng, Y., \& Holder, J. S. (2001). Is physical activity or physical fitness more important in defining health benefits? Medicine and Science in Sports and Exercise, $33(6$ Suppl), S379-399.

Boreham, C. A., Twisk, J., Savage, M. J., Cran, G. W., \& Strain, J. J. (1997). Physical activity, sports participation, and risk factors in adolescents. Medicine and Science in Sports and Exercise, 29(6), 788-793.

Bouchard, C., \& Rankinen, T. (2001). Individual differences in response to regular physical activity. Medicine and Science in Sports and Exercise, 33(6 Suppl), S446-451.

Caspersen, C. J., Pereira, M. A., \& Curran, K. M. (2000). Changes in physical activity patterns in the United States, by sex and cross-sectional age. Medicine and Science in Sports and Exercise, 32(9), 1601-1609.

Chen, L. J., Fox, K. R., Haase, A., \& Wang, J. M. (2006). Obesity, fitness and health in Taiwanese children and adolescents. European Journal of Clinical Nutrition, 60(12), 1367-1375 
Church, T. S., Earnest, C. P., Skinner, J. S., \& Blair, S. N. (2007). Effects of different doses of physical activity on cardiorespiratory fitness among sedentary, overweight or obese postmenopausal women with elevated blood pressure: A randomized controlled trial. Journal of the Americal Medinine Association, 297(19), 2081-2091.

Ekelund, U., Poortvliet, E., Nilsson, A., Yngve, A., Holmberg, A., \& Sjöström, M. (2001). Physical activity in relation to aerobic fitness and body fat in 14- to 15-year-old boys and girls. European Journal of Applied Physiology, 85(3), 195-201.

Haase, A., Steptoe, A., Sallis, J. F., \& Wardle, J. (2004). Leisure-time physical activity in university students from 23 countries: associations with health beliefs, risk awareness, and national economic development. Preventive Medicine, 39(1), 182-190.

Hallal, P. C., Victora, C. G., Wells, J. C., \& Lima, R. C. (2003). Physical inactivity: prevalence and associated variables in Brazilian adults. Medicine and Science in Sports and Exercise, 35(11), 1849-1900.

Howley, E. T. (2001). Type of activity: resistance, aerobic and leisure versus occupational physical activity. Medicine and Science in Sports and Exercise, 33(6), S364-369.

Huang, Y., \& Malina, R. (2007). BMI and health-related physical fitness in Taiwanese youth 9-18 years. Medicine and Science in Sports and Exercise, 39(4), 701-708.

Katzmarzyk, P.T., Malina, R.M., Song, T.M.K, \& Bouchard, C. (1998). Physical activity and health-related fitness in youth: A multivariate analysis. Medicine and Science in Sports and Exercise, 30, 709-714.

Liou, Y.M., Hung, Y.T., Chang, P., Chiang, L.C., Huang, L.H., Chen, J.J., Yao, K. P., \& Chu, T.H. The establishment of the surveillance system and international cooperation of the international physical activity questionnaires (BHP-92-6-007, DOH-93-HP1410, BHP94-CH1-001). Taipei: The grate report of 2004-2006. Bureau of Health Promotion, Department of Health, Taiwan, R.O.C.
Malina, R., M (2001). Physical activity and fitness: Pathways from childhood to adulthood. American Journal of Human Biology, 13(2), 162-172.

Ortega, F. B., Ruiz, J. R., Castillo, M. J., \& Sjostrom, M. (2007). Physical fitness in childhood and adolescence: a powerful marker of health. International Journal of Obesity. Epub ahead of print.

Sparling, P. B. (2003). College physical education: an unrecognized agent of change in combating inactivityrelated diseases. Perspectives in Biology and Medicine, 46(4), 579-587.

U.S. Department of Health and Human Services. (1996). Physical Activity and Health: A Report of the Surgeon General. Atlanta, GA: U.S. Department of Health and Human Services, Centers for Disease Control and Prevention, National Center for Chronic Disease Prevention and Health Promotion.

Vandelanotte, C., Spathonis, K. M., Eakin, E. G., \& Owen, N. (2007). Website-delivered physical activity interventions: A review of the literature. American Journal of Preventive Medicine, 33(1), 54-64.

Wantland, J. D., Portillo, J. C., Holzemer, L. W., Slaughter, R., \& McGhee, M. E. (2004). The effectiveness of web-based vs. non-web-based interventions: A metaanalysis of behavioral change outcomes. Journal of Medical Internet Research, 6(4), e40.

\section{Correspondence:}

Shu-Chen Chen

Department of Recreation Sport Management,

Yu-Da College of Business,

168 Hsueh-fu Rd, Tanwen Village,

Chaochiao Township, Miaoli County,

36143 Taiwan, ROC.

Telephone: 886-37-651188 ext. 5581;

Fax: 886-37-652146

E-mail: scchen@ydu.edu.tw 